\title{
Microencapsulation as a novel delivery method for the potential antidiabetic drug, Probucol
}

\author{
Armin Mooranian' \\ Rebecca Negrulj' \\ Nigel Chen-Tan ${ }^{2}$ \\ Hesham S Al-Sallami ${ }^{3}$ \\ Zhongxiang Fang ${ }^{4}$ \\ TK Mukkur ${ }^{5}$ \\ Momir Mikov 6,7 \\ Svetlana Golocorbin-Kon ${ }^{6,7}$ \\ Marc Fakhoury ${ }^{8}$ \\ Gerald FWatts ${ }^{9}$ \\ Vance Matthews ${ }^{10}$ \\ Frank Arfuso ${ }^{5}$ \\ Hani Al-Salami'
}

'Biotechnology and Drug Development Research Laboratory School of Pharmacy, Curtin Health

Innovation Research Institute, Biosciences

Research Precinct, Curtin University, Perth,

Western Australia, Australia; ${ }^{2}$ Faculty of Science

and Engineering, Curtin University, Perth,

Western Australia, Australia; ${ }^{3} \mathrm{~S}$ chool of Pharmacy,

University of Otago, Dunedin, New Zealand;

${ }^{4}$ School of Public Health, Curtin University, Perth,

Western Australia, Australia; ${ }^{5}$ Curtin Health

Innovation Research Institute, Biosciences

Research Precinct, School of Biomedical Science,

Curtin University, Perth, Western Australia,

Australia; ${ }^{6}$ Department of Pharmacology,

Toxicology and Clinical Pharmacology, Faculty

of Medicine, University of Novi Sad, Serbia;

${ }^{7}$ Department of Pharmacy, Faculty of Medicine,

University of Novi Sad, Serbia; ${ }^{8}$ Faculty of

Medicine, University of Montreal, Montreal,

Quebec, Canada; ${ }^{9}$ School of Medicine and

Pharmacology, Royal Perth Hospital, University

of Western Australia; ${ }^{10}$ Laboratory for Metabolic

Dysfunction, UWA Centre for Medical Research,

Harry Perkins Institute of Medical Research,

Perth, Western Australia, Australia

Correspondence: Hani Al-Salami

Biotechnology and Drug Development

Research Laboratory, Curtin Health Innovation

Research Institute, Biosciences Research

Precinct, Curtin University, Kent Street,

Bentley WA 6102, Perth,

Western Australia, Australia

Tel +6I 892669816

Fax +6I 892662769

Email hani.al-salami@curtin.edu.au
This article was published in the following Dove Press journal:

Drug Design, Development and Therapy

9 September 2014

Number of times this article has been viewed

Introduction: In previous studies, we successfully designed complex multicompartmental microcapsules as a platform for the oral targeted delivery of lipophilic drugs in type 2 diabetes (T2D). Probucol (PB) is an antihyperlipidemic and antioxidant drug with the potential to show benefits in T2D. We aimed to create a novel microencapsulated formulation of PB and to examine the shape, size, and chemical, thermal, and rheological properties of these microcapsules in vitro.

Method: Microencapsulation was carried out using the Büchi-based microencapsulating system developed in our laboratory. Using the polymer, sodium alginate (SA), empty (control, SA) and loaded (test, PB-SA) microcapsules were prepared at a constant ratio (1:30). Complete characterizations of microcapsules, in terms of morphology, thermal profiles, dispersity, and spectral studies, were carried out in triplicate.

Results: PB-SA microcapsules displayed uniform and homogeneous characteristics with an average diameter of $1 \mathrm{~mm}$. The microcapsules exhibited pseudoplastic-thixotropic characteristics and showed no chemical interactions between the ingredients. These data were further supported by differential scanning calorimetric analysis and Fourier transform infrared spectral studies, suggesting microcapsule stability.

Conclusion: The new PB-SA microcapsules have good structural properties and may be suitable for the oral delivery of PB in T2D. Further studies are required to examine the clinical efficacy and safety of PB in T2D.

Keywords: artificial cell microencapsulation, diabetes, antioxidant, anti-inflammatory, Probucol

\section{Introduction}

Diabetes mellitus (DM) is a metabolic disorder that affects millions of people globally. The prevalence of DM is increasing worldwide at an alarming rate because of lifestyle changes, aging, urbanization, increasing obesity, and physical inactivity. ${ }^{1,2} \mathrm{DM}$ is classified mainly as type 1 diabetes (T1D) or type 2 diabetes (T2D). ${ }^{3}$ T2D develops because of genetic and environmental factors that lead to tissue desensitization to insulin. ${ }^{4}$ Antidiabetic drugs are commonly used and are effective in minimizing variations between peaks and troughs of blood glucose levels in diabetic patients. However, $\beta$ cell damage, coupled to the build-up of free radicals and toxins, remain detrimental factors in the treatment of the disease and its complications. ${ }^{5}$ Thus, there is a real need for new and more efficacious medications for diabetes, which are capable of exerting a stronger protection of $\beta$ cells and have substantial anti-free radical and antioxidant effects.

Probucol (PB) (Sigma-Aldrich Co., St Louis, MO, USA) is a highly lipophilic (dissociation constant, $\left.\mathrm{pk}_{\mathrm{a}}=10.24\right)$ drug that has been shown to protect $\beta$ cells of the pancreas 
through its strong anti-free radical and antioxidant effects, thereby neutralizing reactive oxygen species and alleviating oxidative stress. ${ }^{6,7} \mathrm{~PB}$ was developed as an antihyperlipidemic drug but was withdrawn in some countries because of high interindividual variation in absorption and potentially severe adverse effects. ${ }^{8}$ PB is still in use in a few countries, mainly for familial hypercholesterolemia in combinations with statins. PB accumulates extensively in adipose tissues and is primarily eliminated via the fecal route. ${ }^{9}$ PB's elimination half-life is highly variable between individuals and is estimated to range from 23 to more than 50 days. An early study reported that hypercholesterolemic patients treated with $\mathrm{PB}$ were found to have plasma levels of PB averaging $98 \mu \mathrm{M} .{ }^{10}$ Peak plasma concentrations are also significantly variable, and the time to reach maximum concentration in plasma is between 8-24 hours after an oral dose.

PB concentrations in adipose tissues are 100 times higher than that in plasma, resulting in multicompartmental distribution and multiphasic excretion pathways. ${ }^{11,12}$ The exact metabolic fate of PB is unknown, but several compounds have been identified in the plasma, although its exact biotransformation pathways remain elusive. ${ }^{13}$ As the major route of elimination is the bile and feces, renal clearance is very low (2\%). ${ }^{13,14}$ In one study, gelatin-acacia microcapsules were prepared by using a special coacervation method and were studied for encapsulating microdroplets of oil solution containing PB; this resulted in better bioavailability. ${ }^{15}$ PB's low and variable oral bioavailability, and its nonlinear distribution and clearance, contribute to the variability in its pharmacokinetic (PK) and pharmacodynamic properties, as well as its adverse effects. ${ }^{16,17}$ Thus, despite its huge potential, its variable and poor absorption kinetics remain major obstacles to its potential use in T2D. ${ }^{16}$

Designing a novel and stable formulation with good rheological parameters is anticipated to overcome these obstacles. This can be achieved by using artificial cell microencapsulation (ACM) technology.

Since the innovation of ACM technology by Thomas Chang at McGill University in Canada in the 1960s, this technology has been used worldwide by many researchers, scientists, and translational entrepreneurs, using biodegradable polymers such as sodium alginates. ACM has been used significantly in the delivery of various cells and therapeutics. ${ }^{18,19}$ ACM is commonly used to improve the delivery of lipophilic drugs that exhibit low bioavailability and poor dissolution and absorption kinetics. ${ }^{20}$ In the process of microencapsulation, the microcapsules encapsulate a drug using a biodegradable polymer (such as sodium alginate), which protects it from the hostile environment of the gastrointestinal tract, and provides a $\mathrm{pH}$-sensitive targeted delivery. The choice of a polymer has a significant effect on the formulation properties and efficacy, as well as on the drug's chemical and thermal characteristics. ${ }^{21}$ Previous work by our research group ${ }^{20,22-29}$ on the formulation of the antidiabetic drug gliclazide, alone or combined with bile acids (in vitro and in vivo), and our recently designed and formulated microcapsules platform have demonstrated improved PK and pharmacodynamic responses when using a sodium alginate-based formulation. Thus, this study aimed to examine the suitability of our newly developed microcapsules in producing a novel and a stable PB formulation suitable for oral delivery in T2D.

\section{Materials and methods Materials}

PB (98\%) and low-viscosity sodium alginate (LVSA, 99\%) were purchased from Sigma-Aldrich Co., St Louis, MO, USA. Calcium chloride dihydrate $\left(\mathrm{CaCl}_{2} \cdot 2 \mathrm{H}_{2} 0,98 \%\right)$ was obtained from Scharlab SL (Barcelona, Spain). All solvents and reagents were supplied by Merck \& Co, Inc. (Whitehouse Station, NJ, USA) and were of high-performance liquid chromatography (HPLC) grade and used without further purification.

\section{Drug preparations}

Stock suspensions of PB $(20 \mathrm{mg} / \mathrm{mL})$ were prepared by adding the powder to $10 \%$ ultra water-soluble gel of $100 \mathrm{~mL}$ HPLC water. The gel is an ultrasonic gel mixed in HPLC water. The $\mathrm{CaCl}_{2}$ stock solution $(2 \%)$ was prepared by adding $\mathrm{CaCl}_{2}$ dihydrate to HPLC water. All preparations were mixed thoroughly at room temperature for 4 hours, stored in the refrigerator, and used within 48 hours of preparation.

\section{Preparation of microcapsules}

Microcapsules of PB-loaded LVSA were prepared with a Büchi-based microencapsulating system (Büchi Labortechnik, Flawil, Switzerland), using a jet-flow microencapsulation technique, as described elsewhere. ${ }^{28}$ Parameters were set in a frequency range of $1,000-1,500 \mathrm{~Hz}$ and a flow rate of $4 \mathrm{~mL} / \mathrm{minute}$ under a constant air pressure of $300 \mathrm{mbar}$. Polymer solutions containing LVSA with or without PB were made up to a final concentration (of PB-SA) in a ratio of $1: 30 .{ }^{23}$ Microcapsules were fabricated in the form of hydrosol mixture, and for each formulation (unloaded and PB loaded), three independent batches were prepared and tested separately $(n=3)$. All microcapsules (of both formulations) were prepared and treated in the exact same way. Microcapsules were dried 
by using the Stability Chambers (Angelantoni Environmental and Climatic Test Chamber, Massa Martana, Italy).

\section{Characterization of PB-loaded microcapsules \\ Morphology, size analysis, and chemical characterization of microcapsules}

All microcapsules were freshly made, stored in the refrigerator, and used within 48 hours of preparation. The appearance and size of microcapsules were examined using light microscopy, followed by scanning electron microscopy and energy-dispersive X-ray spectrometry (EDXR). The particle size distribution and mean particle size diameter were calculated using the instruments' software provided. Membrane width was measured via microcapsule's cross-section measurements, using the mounted ToupTek (Zhejiang, People's Republic of China) photonics FMA050 fixed calibrated microscope adaptor.

\section{Optical microscopy}

Morphological characteristics and particle size analysis were determined using a Nikon YS2-H (Tokyo, Japan) mounted with a ToupTek photonics FMA050 fixed calibrated microscope adaptor. Sample analysis was carried out in triplicates. Briefly, predetermined quantities (10 microcapsules from each formulation) of freshly prepared microcapsules were loaded onto a glass slide mounted to a calibrated scale. Optical microscopy software (ToupTek) capable of particle size analysis, microcapsule characterization, and morphological assessments was used to determine basic characteristics of the microcapsules to complement the scanning electron microscopy (SEM) studies.

\section{SEM and EDXR spectroscopy}

The surface morphology of the microcapsules was examined using SEM (Neon 40EsB FIB-SEM; Zeiss, Oberkochen, Germany) with $0.8 \mathrm{~nm}$ calibrated resolution. The chemical characterization of the microcapsules was examined using EDXR (INCA X-Act; Oxford Instruments, Abingdon, United Kingdom). Electron micrographs of PB-loaded microcapsules and empty SA microcapsules were obtained using SEM, and their chemical characterization was obtained using EDXR. The samples were mounted on a glass stub with double-sided adhesive tape and coated under vacuum with platinum $(5 \mathrm{~nm})$ in an argon atmosphere before examination. Micrographs with different magnifications were recorded to study the morphological and surface characteristics of the microcapsules.

\section{Determination of dispersing media viscosity}

Viscosities of both preparations (SA and PB-SA) were measured for freshly prepared mixtures, using $15 \mathrm{~mL}$ aliquots $(\mathrm{n}=3)$ at room temperature and using Visco- 88 viscometry (Bohlin-Visco 88; Malvern Instruments). The temperature remained constant at $23^{\circ} \mathrm{C}$ (monitored by the Visco 88).

\section{Differential scanning calorimetric analysis}

Differential scanning calorimetry (DSC) thermograms of $\mathrm{PB}$, LVSA powder (a physical powder mixture of $\mathrm{PB}$ and LVSA), and PB-loaded microcapsules were carried out in a DSC instrument (DSC 8000; PerkinElmer Inc., Waltham, MA, USA). Briefly, $5 \mathrm{mg}$ samples were placed in sealed aluminium pans and heated at $20^{\circ} \mathrm{C} /$ minute under a nitrogen atmosphere (flow rate, $30 \mathrm{~mL} /$ minute) in the $35^{\circ} \mathrm{C}-240^{\circ} \mathrm{C}$ range. An empty aluminium pan was used as a reference. The equipment was calibrated for baseline and temperature, using zinc metal.

\section{Fourier transform infrared spectral studies}

Fourier transform infrared (FTIR) spectra of pure components, their physical mixture, and the PB-loaded microcapsules were recorded via attenuated total reflectance FTIR spectrometer TWO (PerkinElmer), and infrared measurements were performed in transmission in the scanning range of $650-4,000 \mathrm{~cm}^{-1}$ at room temperature. The PB:polymer ratio to those analytically determined in the microcapsules was used for preparing the different physical mixtures that were used as control.

\section{Results and discussion Morphology, size analysis, and chemical characterization of microcapsules}

Microcapsules were obtained using LVSA polymer and PB at a constant ratio of 1:30. The mean diameters ranged from $1,100-1,295 \mu \mathrm{m}$ for all batches of the formulation. The average size was slightly above $1,000 \mu \mathrm{m}$ in diameter, rendering them macroparticles.

\section{Optical microscopy}

A predetermined amount of microcapsules from the SA and PB-SA formulation was selected for particle size and morphological analysis. Microcapsules revealed uniform consistency and spherical shapes with similar sizes, as determined via a calibrated scale mounted onto a glass slide. The mean diameter of PB microcapsules (average \pm standard deviation) was $1,195 \pm 98 \mu \mathrm{m}$ (Figure 1). The vertical diameter (L1) and 

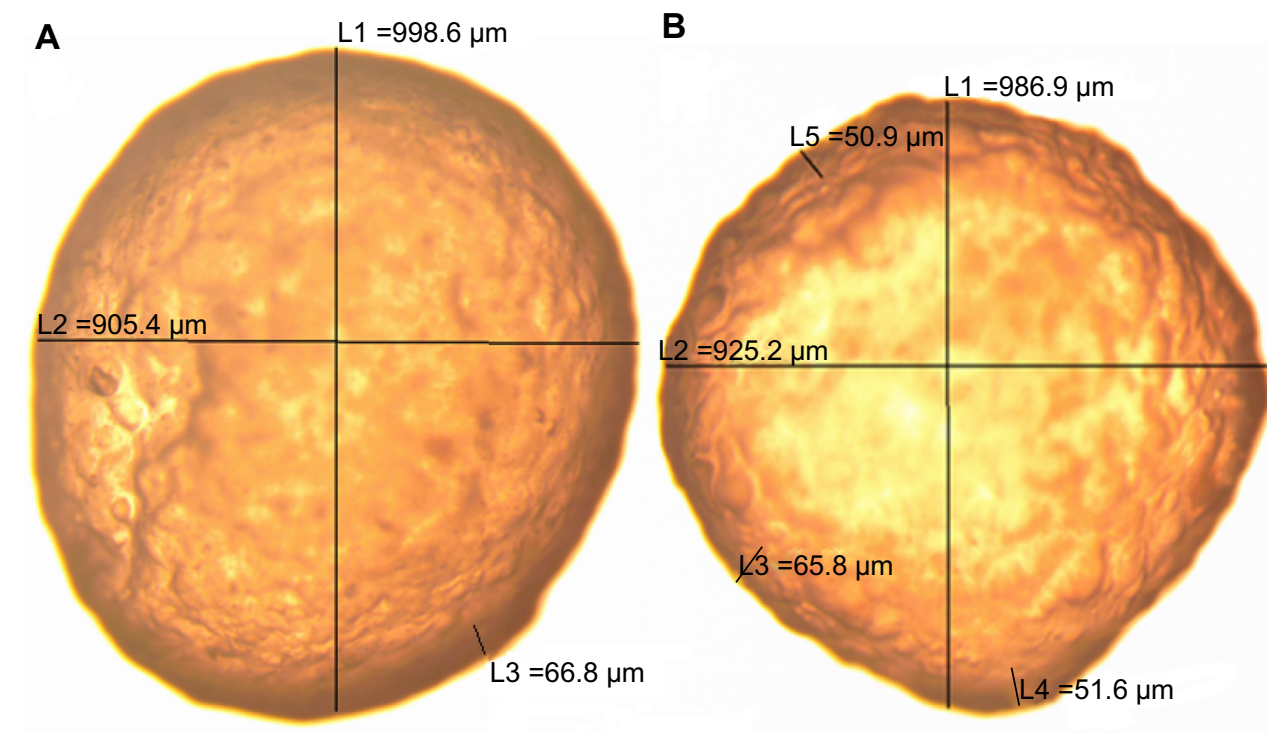

Figure I Probucol microcapsules (A) and sodium alginate microcapsule (B).

Notes: LI and L2 are vertical diameter and horizontal diameter, and L3, L4, and L5 are membrane width thickness at different positions of the microcapsules, respectively. Probucol manufactured by Sigma-Aldrich Co., St Louis, MO, USA.

horizontal diameter (L2) were also measured, along with membrane width (L3, L4, and L5), as shown in Figure 1.

\section{SEM}

Results from optical microscopy revealed opaque, discrete, and spherical microcapsules with homogeneous particle size distribution. This was further supported by SEM studies of the PB microcapsule (Figures 2 and 3), which represented randomly selected microcapsules from a few batches using $200,10,3$, and $2 \mu \mathrm{m}$ scales. Figure $3 \mathrm{~B}$ and $3 \mathrm{D}$ had close magnifications, but because of the different angles used, they showed different morphology. In addition, SEM results show

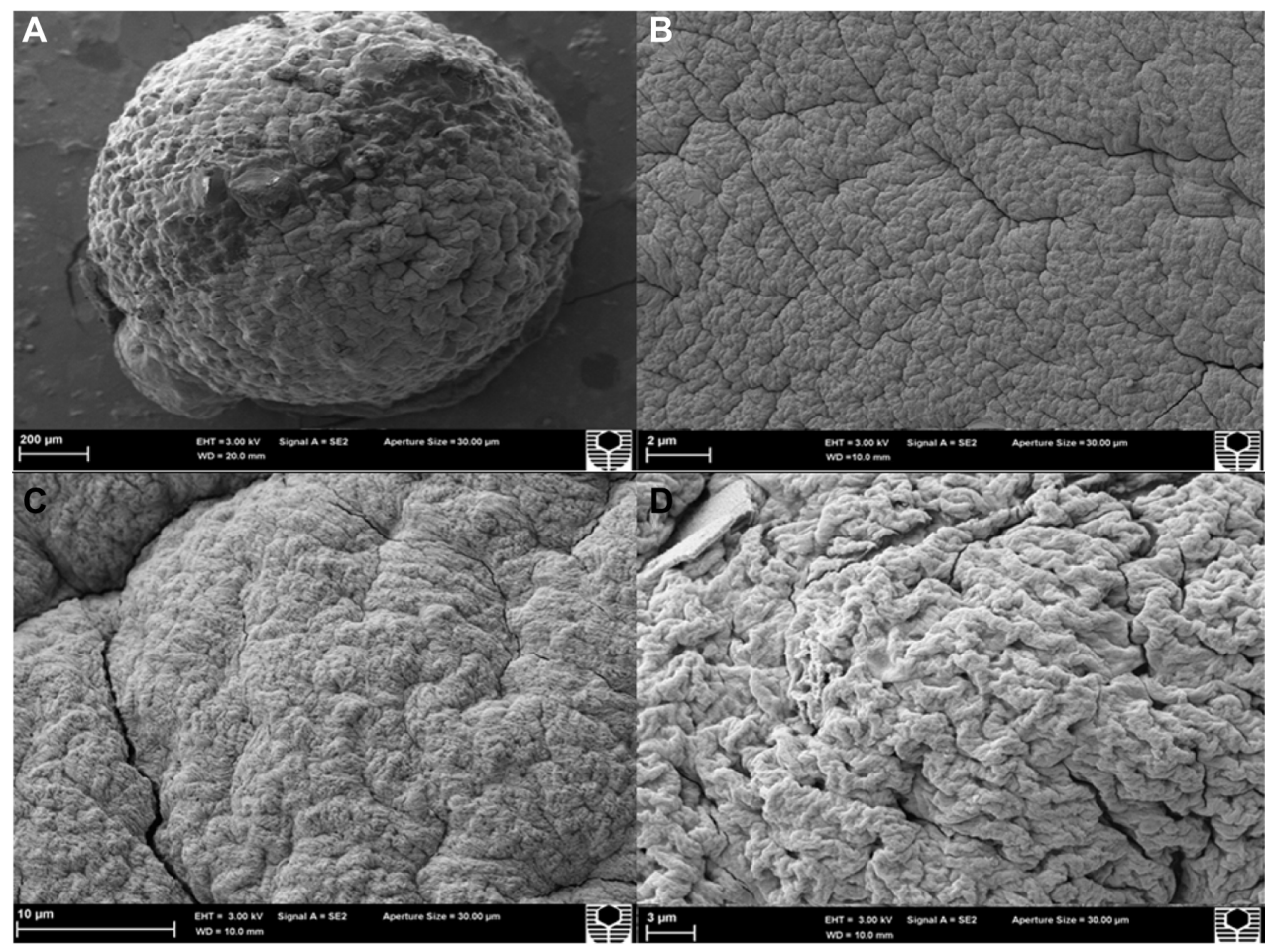

Figure 2 Scanning electron micrographs.

Notes: Sodium alginate microcapsule at $200 \mu \mathrm{m}$ scale (A); surface morphology at $2 \mu \mathrm{m}$ scale (B), $10 \mu \mathrm{m}$ scale (C), and $3 \mu \mathrm{m}$ scale (D). 


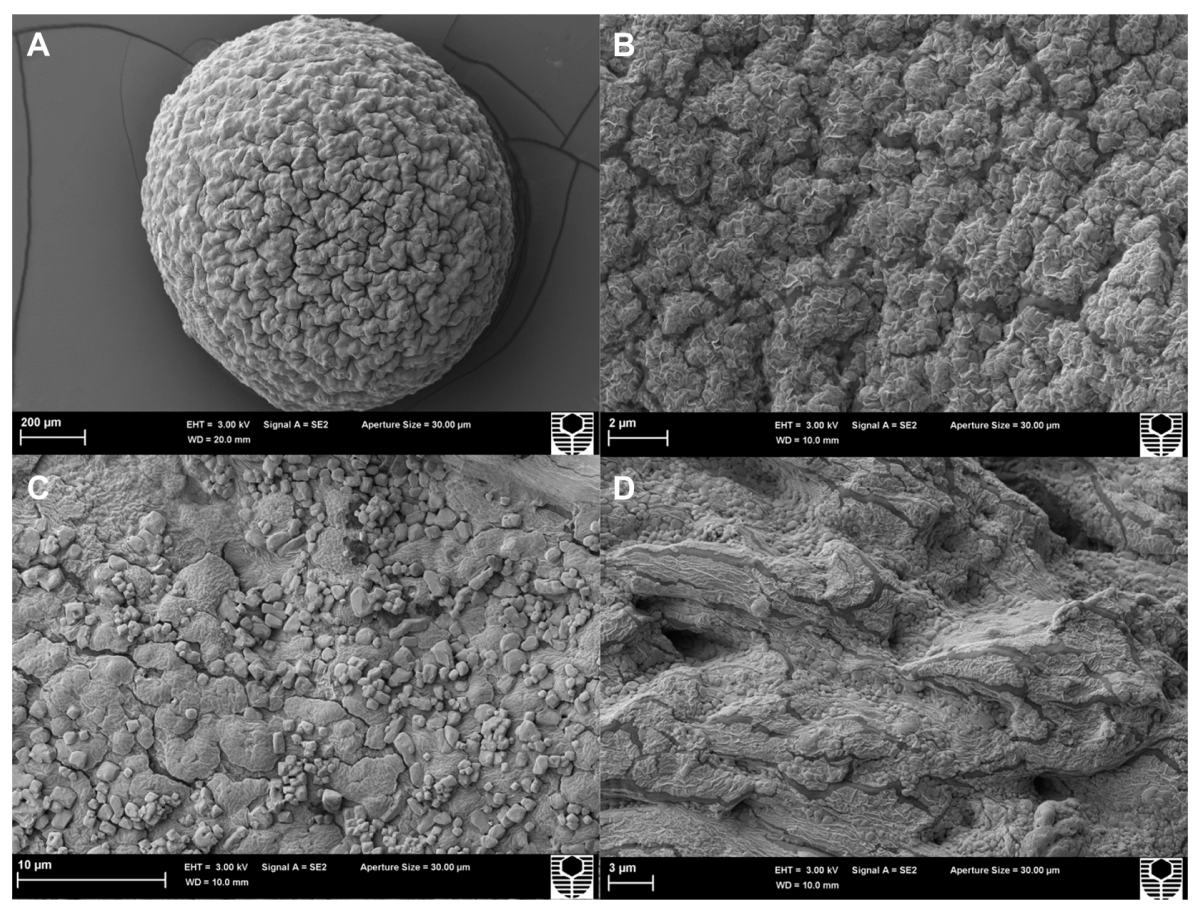

Figure 3 Scanning electron micrographs.

Notes: Probucol-sodium alginate microcapsule at $200 \mu \mathrm{m}$ scale (A); surface morphology at $2 \mu \mathrm{m}$ scale (B), $10 \mu \mathrm{m}$ scale (C), and at $3 \mu \mathrm{m}$ scale (D). Probucol manufactured by Sigma-Aldrich Co., St Louis, MO, USA.

microcapsules of consistent uniformity and well-defined spherical shapes. Because of the high-resolution images, we were able to conclude that the surfaces of the microcapsules were rough but consistent from one microcapsule to another in all analyzed batches. Interestingly, small crystals were distributed throughout the microcapsule surfaces, either as large clumps or as smaller ones. These crystals coating the microcapsule surface were believed to be the drug, PB, which was confirmed by EDXR results (Figures 4, 5, and 7). However, PB present in the surface could be crystal or amorphous phase.

\section{EDXR}

To further analyze the composition of the microcapsule surface, EDXR was used to identify the various surface crystal
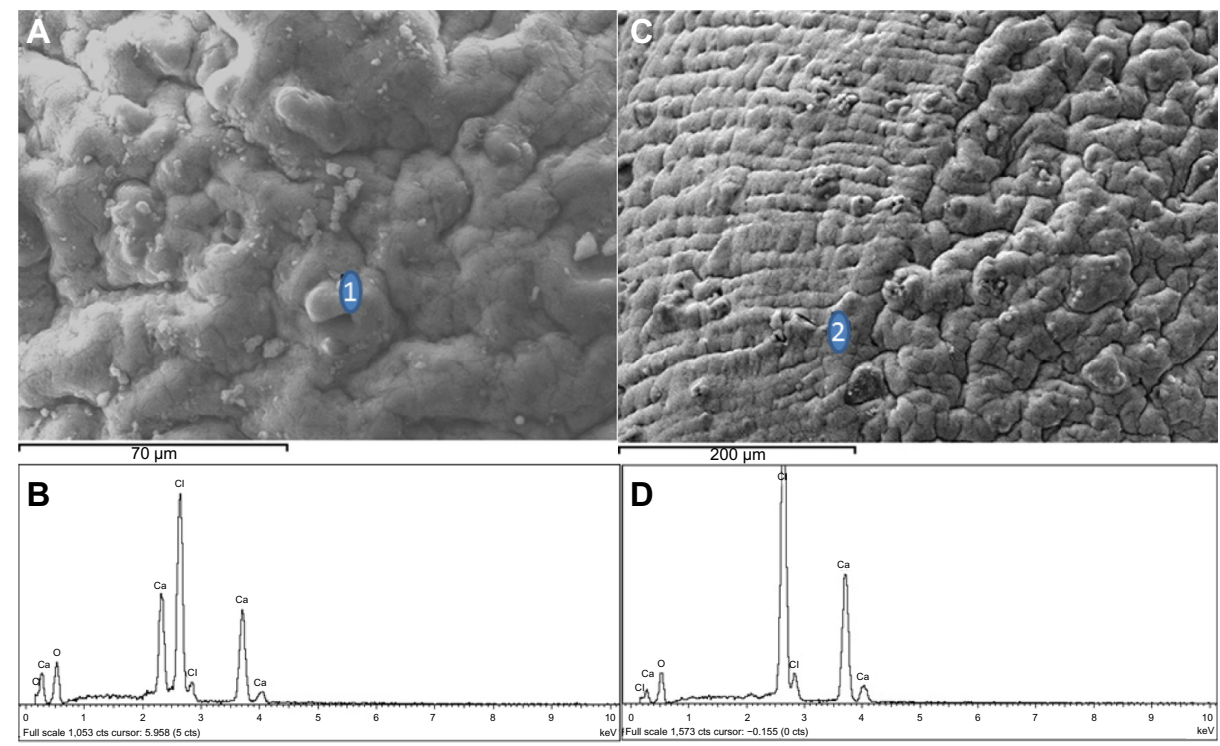

Figure 4 Energy-dispersive $X$-ray spectra of sodium alginate microcapsules' surface.

Notes: Showing crystal deposition (A, I) and surface composition $(\mathbf{C}, 2)$, with corresponding analysis (B and $\mathbf{D})$. Note that no sulfur atoms were detected because no Probucol was in this formulation. 


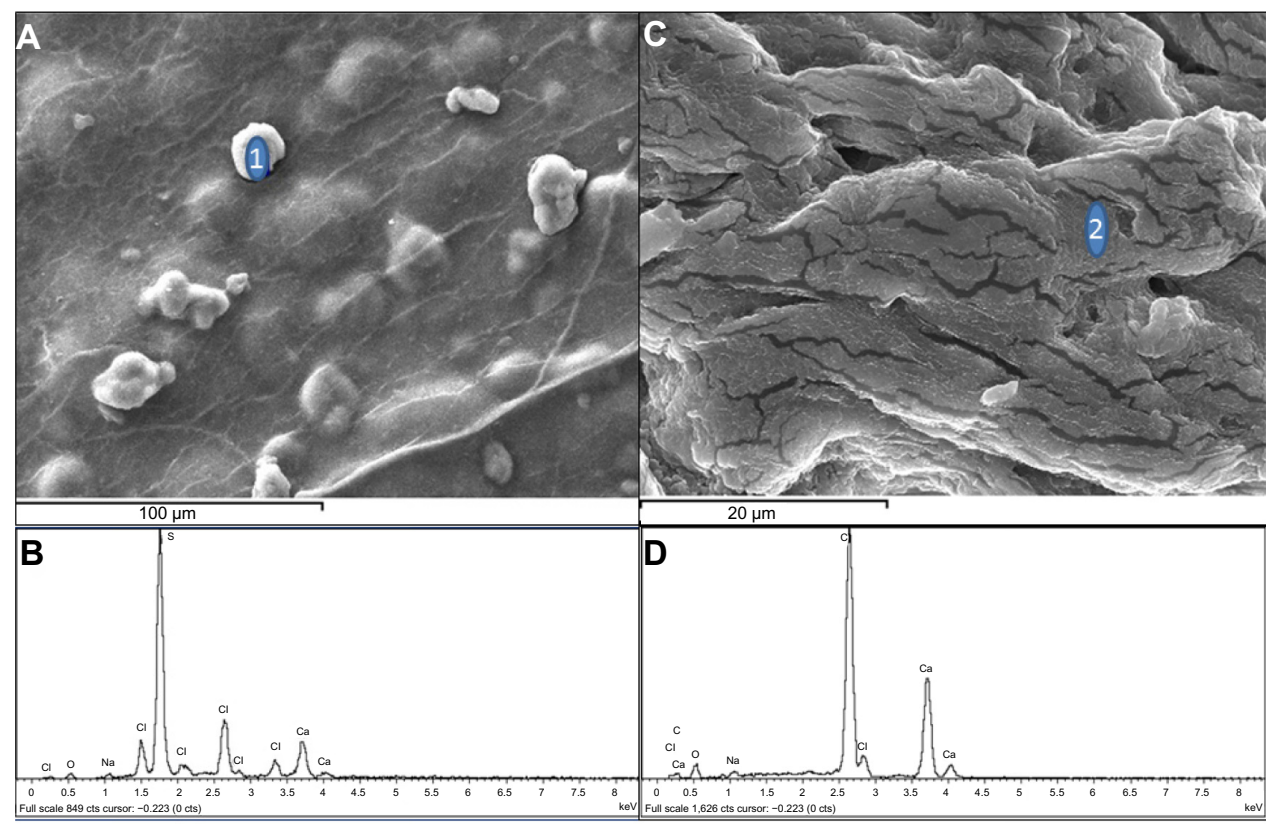

Figure 5 Energy-dispersive X-ray spectra of Probucol-sodium alginate microcapsules surface.

Notes: Drug deposition (A, I) and surface composition $(\mathbf{C}, 2)$ with corresponding analysis (B and $\mathbf{D})$. The presence of drug crystals and corresponding sulfur atoms detected confirm the presence of Probucol in this formulation. Probucol manufactured by Sigma-Aldrich Co., St Louis, MO, USA.

depositions and microcapsule surface composition. The coating materials ( $\mathrm{Pt}$ and $\mathrm{Zr}$ ) have been neutralized in the analysis by the instrument. Analysis of crystal depositions on the microcapsule surfaces (Figures 4 and 5) revealed high levels of sulfur atoms, confirming that the small crystals noted on the surface of PB-SA microcapsules were that of PB (as no other compound used in the formulation contains the sulfur atom). ${ }^{30}$ It appears from SEM coupled with EDXR analyses that $\mathrm{PB}$ preferentially coats the microcapsule surface, forming scattered clumps of drug agglomerates distributed around the microcapsule surface.

EDXR assessment for two different surface sites of a SA microcapsule is shown in Figure 4, with its corresponding analysis. As can be seen, the surface is largely made up of calcium and oxygen atoms, which is expected for microcapsules produced using the ionic gelation method (surface composition is largely calcium alginate).

An example of an EDXR assessment of PB-SA microcapsules is shown in Figure 5, with the respective spectrum of the microcapsule surface. The microcapsule surfaces were not perfectly homogeneous, and thus, varying crystal depositions occurred at selected sites across the microcapsule surface. Figure 5 shows typical PB-SA microcapsule surface sites where EDXR analysis was conducted (two distinct sections of the microcapsule surface). Two different sites were randomly selected and analyzed (Figures 4A, 4C, 5A and 5C), and the atom composition results (Figures 4B, 4D, 5B and 5D) represent both crystals of drug agglomerates, as well as the surface itself. The spectra of chemical analysis showed the dominant atoms $(\mathrm{Na}, \mathrm{O}$, $\mathrm{Ca}, \mathrm{S}$, and $\mathrm{Cl}$ ) we expected for a typical PB-SA microcapsule prepared via ionic-gelation methodology. The sulfur atom was unique to $\mathrm{PB}$, which showed preferential binding to the microcapsule surface; $\mathrm{Na}$ and $\mathrm{Cl}$ represented sodium chloride, which was the byproduct of ionic gelation and $\mathrm{Ca}$ with $\mathrm{O}$, and was expected, given that the microcapsule surface is composed largely of calcium alginate. ${ }^{31,32}$

\section{Viscosity of the microencapsulated formulation}

Table 1 shows the viscosity, shear rate, shear stress, and torque force for both microencapsulated formulations (SA and PB-SA) under various speeds (20, 35, 61, 107, 187, 327,572 , and 1,000 rpm). No detectable viscosity, torque, or shear stress for the SA formulation was found because the instrument and/or parameters used were not able to detect a significant rheological pattern, despite increasing stirring speeds and shear rate. This is similar to previously published work using the antidiabetic drug, gliclazide, microencapsulated in SA. ${ }^{28}$ However, it was noted that the PB-SA formulation behaved in a non-Newtonian, thixotropic manner, as made evident by parallel reductions in the apparent viscosity with increasing stirring speeds, which was expected. ${ }^{33,34}$ Further evidence of the thixotropic-pseudoplastic behavior 
Table I Viscosities and related parameters of both microencapsulated formulations, sodium alginate and Probucol-sodium alginate ( $\mathrm{n}=3$ )

\begin{tabular}{|c|c|c|c|c|c|}
\hline $\begin{array}{l}\text { Formula code } \\
\text { and set speed }\end{array}$ & RPM & $\begin{array}{l}\text { Viscosity, } \\
\mathrm{mPa} \times \text { seconds }\end{array}$ & $\begin{array}{l}\text { Shear rate, } \\
\text { seconds }^{-1}\end{array}$ & $\begin{array}{l}\text { Torque, } \\
\text { mNm }\end{array}$ & $\begin{array}{l}\text { Shear } \\
\text { stress, Pa }\end{array}$ \\
\hline \multicolumn{6}{|l|}{ Sodium alginate } \\
\hline 1 & 20 & UD & $23.8 \pm 0.2$ & UD & UD \\
\hline 2 & 35 & UD & $42.1 \pm 0.5$ & UD & UD \\
\hline 3 & 61 & UD & $74.4 \pm 0.3$ & UD & UD \\
\hline 4 & 107 & UD & $125 \pm 0.2$ & UD & UD \\
\hline 5 & 187 & UD & $222 \pm 0.3$ & UD & UD \\
\hline 6 & 327 & UD & $385.8 \pm 0.2$ & UD & UD \\
\hline 7 & 572 & UD & $681.8 \pm 0.1$ & UD & UD \\
\hline 8 & 1,000 & UD & $1,197 \pm 3$ & UD & UD \\
\hline \multicolumn{6}{|c|}{ Probucol-sodium alginate } \\
\hline I & 20 & UD & $23.9 \pm 0.3$ & UD & UD \\
\hline 2 & 35 & UD & $42.2 \pm 0.3$ & UD & UD \\
\hline 3 & 61 & UD & $74.5 \pm 0.2$ & $0.08 \pm 0.01$ & UD \\
\hline 4 & 107 & $25 \pm 0.2$ & $125.1 \pm 0.2$ & $0.1 I \pm 0.01$ & $3.2 \pm 0.02$ \\
\hline 5 & 187 & $20 \pm 0.2$ & $222.2 \pm 0.4$ & $0.17 \pm 0.02$ & $4.5 \pm 0.01$ \\
\hline 6 & 327 & $15 \pm 0.3$ & $385.7 \pm 0.3$ & $0.21 \pm 0.03$ & $5.7 \pm 0.03$ \\
\hline 7 & 572 & $10 \pm 0.2$ & $681.8 \pm 0.1$ & $0.26 \pm 0.02$ & $6.9 \pm 0.1$ \\
\hline 8 & 1,000 & $9 \pm 0.3$ & $\mathrm{I}, 194 \pm 4$ & $0.40 \pm 0.03$ & $10.9 \pm 0.01$ \\
\hline
\end{tabular}

Note: Probucol manufactured by Sigma-Aldrich Co., St Louis, MO, USA.

Abbreviations: UD, undetected (below the instrument limit of detection); RPM, revolutions per minute.

of the PB-SA formulation can be seen in the proportional increases in torque and shear rate after rising shear stress forces and an associated decrease in the viscosity characteristic of non-Newtonian fluids and thixotropic behavior of the polymer solutions. ${ }^{35,36}$ The flow behavior of the microcapsules is important when estimating their PK and pharmacodynamic parameters in terms of transit time and $\mathrm{pH}$-targeted delivery after an oral dose..$^{27,32}$ The application of the stirring rod in both solutions at increasing speeds resulted in the solutions forming rapid circular motions away from the site of centripetal force origin, suggesting they behaved in a nonWeissenberg fashion. ${ }^{37,38}$

\section{DSC}

DSC is an important technique for the thermal characterization of various materials. ${ }^{39}$ DSC establishes a connection between temperature and specific physical properties of substances. ${ }^{40,41}$ It is commonly used to determine the enthalpy associated with the process of microencapsulation. In microencapsulation, DSC measures how physical properties of PB molecules change, along with temperature against time. ${ }^{42}$ This occurs through determining the temperature and heat flow $\left(35^{\circ} \mathrm{C}-240^{\circ} \mathrm{C}\right)$ associated with $\mathrm{PB}$ transitions as a function of time. DSC spectra were analyzed for $\mathrm{PB}$ powder (Figure 6A), SA powder (Figure 6B), PB-SA microcapsules (Figure $6 \mathrm{C}$ ), and the combined physical powder mixture PB-SA (Figure 6D).
PB has at least two polymorphs with different crystal lattice structures and molecular configurations. ${ }^{43,44}$ Form I (melting point, $125^{\circ} \mathrm{C}$ ) is substantially more thermodynamically stable than form II (melting point, $116^{\circ} \mathrm{C}$ ).$^{44} \mathrm{DSC}$ analysis of $\mathrm{PB}$ powder (Figure 6A) shows a peak of $128^{\circ} \mathrm{C}$, which is indicative of the melting point of the compound, in accordance with published work. ${ }^{45}$ Importantly, we were able to conclude that the PB sample acquired from our supplier was form I and not form II. The thermogram of sodium alginate powder was also in line with previously published work and was indicative of the polymer's melting point. ${ }^{46}$ For the combined physical powder mixture, the thermogram included both the PB melting peak and that of the polymer, which indicated that SA retained its amorphous polymer structure and PB's crystalline form and was not modified on physical mixing. The DSC analysis of the PB-SA microcapsules (Figure 6C) revealed two distinct peaks. The peak at $127^{\circ} \mathrm{C}$ clearly depicts $\mathrm{PB}$, whereas the peak at $213^{\circ} \mathrm{C}$ was a marginal shift to the right when compared with SA powder $\left(193^{\circ} \mathrm{C}\right.$, as seen in Figure 6B) and could represent plasticization of the polymer. ${ }^{46}$ PB was not chemically modified by and did not participate in any reaction with the polymer used in the formulation, as evident by endothermic peaks characteristic of the drug after analysis of the microcapsules. After microencapsulation, PB retained its chemical integrity and crystal lattice structure, as confirmed by both DSC and FTIR results (Figure 7); thus, full compatibility was evident. In addition, PB form I was 
A

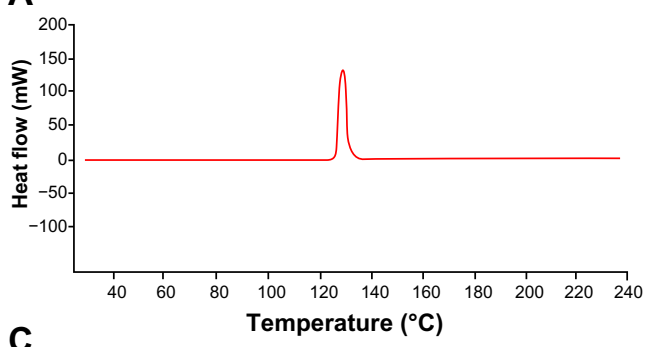

C

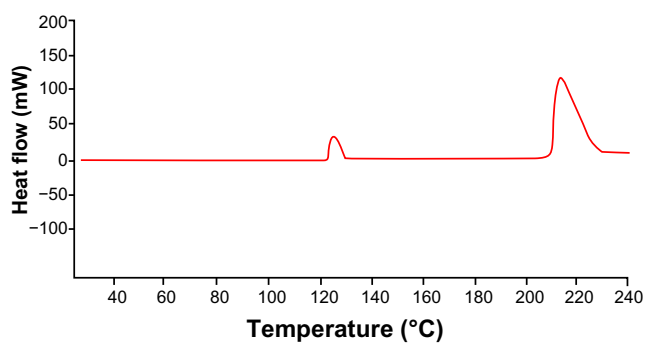

B
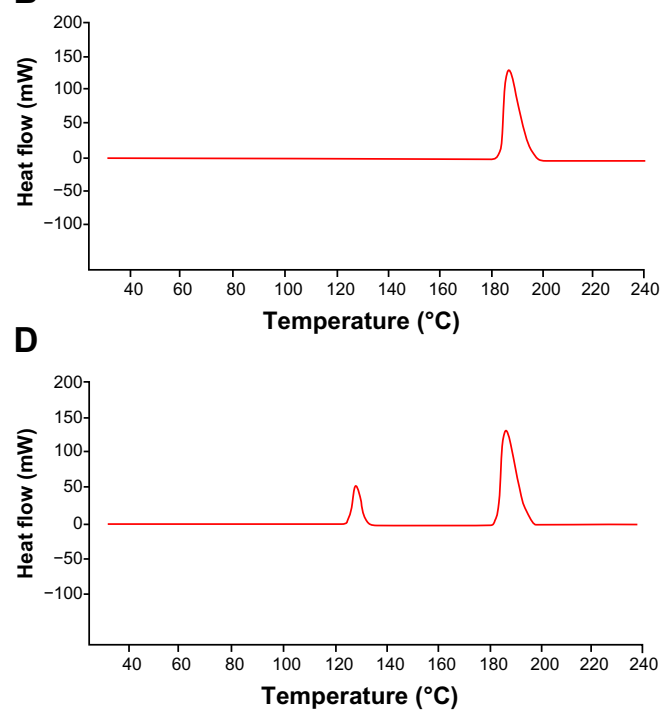

Figure 6 Differential scanning calorimetric thermograms.

Notes: Probucol powder (A), sodium alginate powder (B), Probucol-sodium alginate microcapsule (C), and Probucol-sodium alginate powder (D). Probucol manufactured by Sigma-Aldrich Co., St Louis, MO, USA.

maintained throughout the microencapsulation procedure, and thus, thermodynamic stability was also maintained.

The two distinct peaks detected on the DSC analysis of PB-SA microcapsules and PB-SA powder (Figure 6D; one for Probucol and the other being alginate) raise the notion that the drug was not solubilized in the matrix system of the microcapsules; otherwise, any PB-alginate interactions would have resulted in "disappearance" of the thermogram for PB, and new chemical bonding groups would have been detected on FTIR investigations. ${ }^{42,44}$ Hence, low affinity of PB for the alginate-matrix system of the microcapsules resulted in the
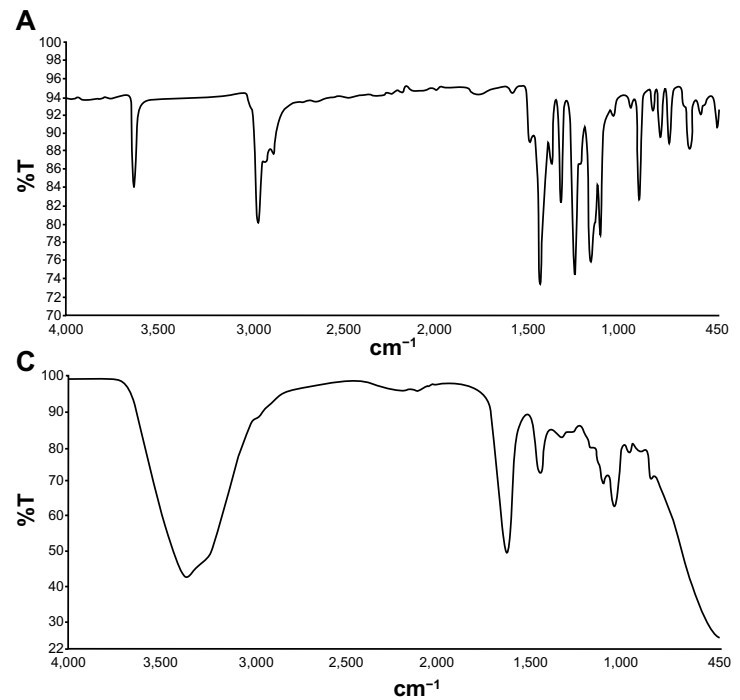

Figure 7 Fourier transform infrared spectra.

Notes: Probucol powder (A), sodium alginate powder (B), Probucol-sodium alginate microcapsule (C), and Probucol-sodium alginate mixed powder (D). Probucol manufactured by Sigma-Aldrich Co., St Louis, MO, USA.

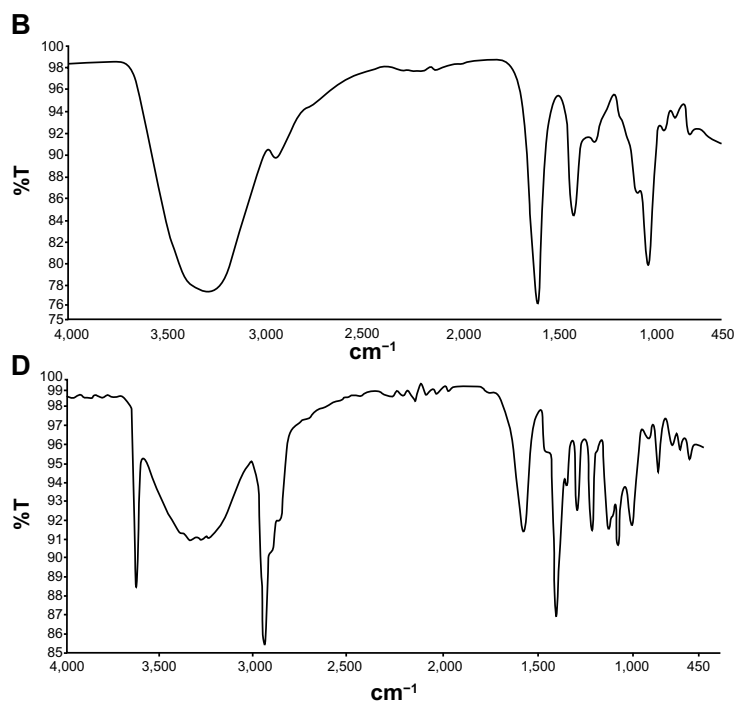

drug preferentially partitioning onto the surface, forming crystal agglomerates that were viewed by SEM analysis and analytically verified via EDXR (Figures 4 and 5). Thus, future work will endeavor to study the stability and drug-release profiles at physiological conditions from these novel microcapsules and determine their feasibility as a delivery system for the effective oral administration of PB in T2D.

\section{FTIR spectral studies}

The FTIR method is widely used to stimulate vibrational levels of known chemical groups in a molecule and induces 
a variation in chemical reactions different to those in thermal analysis, such as DSC. The FTIR spectra were used to confirm the chemical compatibility of PB with the SA polymer in the microencapsulation formulation. FTIR spectra were analyzed for PB powder (Figure 7A), SA powder (Figure 7B), PB-SA microcapsules (Figure 7C), and PB-SA mixture (Figure 7D). FTIR spectral analysis of individual powders, mixed powders containing all the ingredients, and final microcapsules attained is necessary to ensure the chemical compatibility of $\mathrm{PB}$ postmicroencapsulation.

The spectrum of $\mathrm{PB}$ powder (Figure 7A) revealed characteristic peaks at 2,959,1,422, and $1,310 \mathrm{~cm}^{-1}$, which were in line with previously published work. ${ }^{44}$ In addition, the spectrum for SA powder (Figure 7B) was also in accordance with published work, revealing similar peaks. ${ }^{47}$

For the combined powder of PB-SA (Figure 7D), peaks representative of $\mathrm{PB}$ and the polymer were present with no interference, dilution, or alterations in the bond peak activity. This confirmed compatibility of all the ingredients in the powder form, which is the same combination/ proportions as formulated in the drug-polymer solution premicroencapsulation.

The FTIR spectra of the PB-SA microcapsule (Figure 7C) clearly showed two distinct and interferencefree peaks corresponding to $\mathrm{PB}\left(1,426\right.$ and $\left.1,310 \mathrm{~cm}^{-1}\right)$, with the third peak shadowed by the dominant infrared spectral activity of alginate in that region, and three distinct peaks representative of alginate $(3,350,1,602$, and 1,025 $\mathrm{cm}^{-1}$ ). As the DSC and FTIR results depicted no significant changes in the chemical composition of $\mathrm{SA}$ or $\mathrm{PB}$ on microencapsulation, it seems valid to conclude that no chemical reaction or decomposition occurred before and after microencapsulation.

Overall, FTIR spectra of PB suggest that microencapsulation of $\mathrm{PB}$ with $\mathrm{SA}$ does not significantly compromise the chemical composition and structural integrity of the PB molecules because no significant chemical reaction occurred between the drug and any of the formulation excipients.

\section{Conclusion}

Using artificial cell microencapsulation, a novel form of targeted drug delivery of PB with the polymer LVSA displayed optimal excipient compatibility and desired microcapsule size, uniformity, and homogeneity. An interesting future study will be to investigate the release profile, drug entrapment, and stability characteristics of this novel drug delivery for PB microcapsules.

\section{Acknowledgments}

The authors acknowledge the Curtin Health Innovation Research Institute at Curtin University and the Curtinseeding grant for their support and also acknowledge the use of equipment and the scientific and technical assistance of the Curtin University Electron Microscope Facility, which has been partially funded by the university, state, and commonwealth governments. The authors also acknowledge the Pharmaceutical Technology Laboratory for their valuable assistance (Curtin School of Pharmacy).

\section{Disclosure}

The authors report no conflicts of interest in this work.

\section{References}

1. Wild S, Roglic G, Green A, Sicree R, King H. Global prevalence of diabetes: estimates for the year 2000 and projections for 2030. Diabetes Care. 2004;27(5):1047-1053.

2. Chan JC, Malik V, Jia W, et al. Diabetes in Asia: epidemiology, risk factors, and pathophysiology. JAMA. 2009;301(20):2129-2140.

3. Brämer GR. International statistical classification of diseases and related health problems. Tenth revision. World Health Stat Q. 1988;41(1): 32-36.

4. Moore PA, Zgibor JC, Dasanayake AP. Diabetes: a growing epidemic of all ages. JAm Dent Assoc. 2003;134(Spec No):11S-15S

5. Cani PD, Neyrinck AM, Fava F, et al. Selective increases of bifidobacteria in gut microflora improve high-fat-diet-induced diabetes in mice through a mechanism associated with endotoxaemia Diabetologia. 2007;50(11):2374-2383.

6. Wu R, Zhang W, Liu B, et al. Probucol ameliorates the development of nonalcoholic steatohepatitis in rats fed high-fat diets. Dig Dis Sci. 2013;58(1):163-171.

7. Yamashita S, Matsuzawa Y. Where are we with probucol: a new life for an old drug? Atherosclerosis. 2009;207(1):16-23.

8. Shimizu H, Uehara Y, Shimomura Y, Tanaka Y, Kobayashi I. Probucol attenuated hyperglycemia in multiple low-dose streptozotocin-induced diabetic mice. Life Sci. 1991;49(18):1331-1338.

9. Russell JC, Graham SE, Amy RM, Dolphin PJ. Cardioprotective effect of probucol in the atherosclerosis-prone JCR:LA-cp rat. Eur J Pharmacol. 1998;350(2-3):203-210.

10. Parthasarathy S, Young SG, Witztum JL, Pittman RC, Steinberg D Probucol inhibits oxidative modification of low density lipoprotein. J Clin Invest. 1986;77(2):641-644.

11. Matsushita M, Yoshino G, Iwai M, et al. Protective effect of probucol on alloxan diabetes in rats. Diabetes Res Clin Pract. 1989;7(4): 313-316.

12. Liu JH, Liu DF, Wang NN, Lin HL, Mei X. Possible role for the thioredoxin system in the protective effects of probucol in the pancreatic islets of diabetic rats. Clin Exp Pharmacol Physiol. 2011;38(8): 528-533.

13. Blankenhorn DH, Schettler G, Habenicht A. Principles and Treatment of Lipoprotein Disorders. Berlin: Springer; 1994.

14. Buckley MM, Goa KL, Price AH, Brogden RN. Probucol. A reappraisal of its pharmacological properties and therapeutic use in hypercholesterolaemia. Drugs. 1989;37(6):761-800.

15. Jizomoto H, Kanaoka E, Sugita K, Hirano K. Gelatin-acacia microcapsules for trapping micro oil droplets containing lipophilic drugs and ready disintegration in the gastrointestinal tract. Pharm Res. 1993;10(8):1115-1122.

16. Zimetbaum P, Eder H, Frishman W. Probucol: pharmacology and clinical application. J Clin Pharmacol. 1990;30(1):3-9. 
17. Heeg JF, Hiser MF, Satonin DK, Rose JQ. Pharmacokinetics of probucol in male rats. J Pharm Sci. 1984;73(12):1758-1763.

18. Chang TM. Microencapsulation of enzymes, cells, and genetically engineered microorganisms. Methods Mol Med. 1999;18:315-330.

19. Chang TM. Pharmaceutical and therapeutic applications of artificial cells including microencapsulation. Eur J Pharm Biopharm. 1998;45(1):3-8.

20. Negrulj R, Mooranian A, Al-Salami H. Potentials and limitations of bile acids in type 2 diabetes mellitus: applications of microencapsulation as a novel oral delivery system. J Endocrinol Diabetes Mellitus. 2013;1(2):49-59.

21. Whelehan M, Marison IW. Microencapsulation using vibrating technology. J Microencapsul. 2011;28(8):669-688.

22. Al-Salami H, Butt G, Fawcett JP, Tucker IG, Golocorbin-Kon S, Mikov M. Probiotic treatment reduces blood glucose levels and increases systemic absorption of gliclazide in diabetic rats. Eur J Drug Metab Pharmacokinet. 2008;33(2):101-106.

23. Al-Salami H, Butt G, Tucker I, et al. Gliclazide reduces MKC intestinal transport in healthy but not diabetic rats. Eur J Drug Metab Pharmacokinet. 2009;34(1):43-50.

24. Al-Salami H, Butt G, Tucker I, Mikov M. Influence of the semisynthetic bile acid MKC on the ileal permeation of gliclazide in vitro in healthy and diabetic rats treated with probiotics. Methods Find Exp Clin Pharmacol. 2008;30(2):107-113.

25. Al-Salami H, et al. The Influence of Pre-Treatment with Probiotics on the in Vitro Ileal Permeation of the Antidiabetic Drug Gliclazide, in Healthy and Diabetic Rats. Drug Metab Rev. 2008;40:81-82.

26. Al-Salami H, Butt G, Tucker I, Skrbic R, Golocorbin-Kon S, Mikov M. Probiotic Pre-treatment Reduces Gliclazide Permeation (ex vivo) in Healthy Rats but Increases It in Diabetic Rats to the Level Seen in Untreated Healthy Rats. Arch Drug Inf. 2008;1(1):35-41.

27. Lalić-Popović M, Vasović V, Milijašević B, Goločorbin-Kon S, Al-Salami H, Mikov M. Deoxycholic Acid as a Modifier of the Permeation of Gliclazide through the Blood Brain Barrier of a Rat. J Diabetes Res. 2013;2013:598603.

28. Mooranian A, Negrulj R, Mathavan S, et al. A complex microencapsulated system: a platform for optimised oral delivery of antidiabetic drug-bile acid formulations. Pharm Dev Technol. 2014:1-8.

29. Mooranian A, Negrulj R, Mathavan S, et al. Stability and Release Kinetics of an Advanced Gliclazide-Cholic Acid Formulation: The Use of Artificial-Cell Microencapsulation in Slow Release Targeted Oral Delivery of Antidiabetics. J Pharm Innov. 2014;9: $150-157$.

30. Davignon J. Probucol. In: Principles and Treatment of Lipoprotein Disorders. Berlin: Springer; 1994:429-469.

31. Awasthi R, Kulkarni GT. Development of novel gastroretentive floating particulate drug delivery system of gliclazide. Curr Drug Deliv. 2012;9(5):437-451
32. Prajapati SK, Tripathi P, Ubaidulla U, Anand V. Design and development of gliclazide mucoadhesive microcapsules: in vitro and in vivo evaluation. AAPS PharmSciTech. 2008;9(1):224-230.

33. Yang Y, Campanella OH, Hamaker BR, Zhang G, Gu Z. Rheological investigation of alginate chain interactions induced by concentrating calcium cations. Food Hydrocoll. 2013;30(1):26-32.

34. de Celis Alonso B, Rayment P, Ciampi E, et al. NMR relaxometry and rheology of ionic and acid alginate gels. Carbohydr Polym. 2010;82(3): 663-669.

35. Draget KI, Taylor C. Chemical, physical and biological properties of alginates and their biomedical implications. Food Hydrocoll. 2011;25(2): 251-256.

36. Bonino CA, Samorezov JE, Jeon O, Alsberg E, Khan SA. Real-time in situ rheology of alginate hydrogel photocrosslinking. Soft Matter. 2011;7(24):11510-11517.

37. Pamies R, Schmidt RR, Martínez MCL, Torre JG. The influence of mono and divalent cations on dilute and non-dilute aqueous solutions of sodium alginates. Carbohydr Polym. 2010;80(1):248-253.

38. Legrand J, Dumont E, Comiti J, Fayolle F. Diffusion coefficients of ferricyanide ions in polymeric solutions - comparison of different experimental methods. Electrochim Acta. 2000;45(11):1791-1803.

39. Gardette JL, Baba M. FTIR and DSC studies of the thermal and photochemical stability of Balanites aegyptiaca oil (Toogga oil). Chem Phys Lipids. 2013;170-171:1-7.

40. Lin SY, Wang SL. Advances in simultaneous DSC-FTIR microspectroscopy for rapid solid-state chemical stability studies: some dipeptide drugs as examples. Adv Drug Deliv Rev. 2012;64(5):461-478.

41. Sarmento B, Ferreira D, Veiga F, Ribeiro A. Characterization of insulinloaded alginate nanoparticles produced by ionotropic pre-gelation through DSC and FTIR studies. Carbohydr Polym. 2006;66(1):1-7.

42. Gill P, Moghadam TT, Ranjbar B. Differential scanning calorimetry techniques: applications in biology and nanoscience. J Biomol Tech. 2010;21(4):167-193.

43. Gerber JJ, Caira MR, Lötter AP. Structures of two conformational polymorphs of the cholesterol-lowering drug probucol. J Crystallogr Spectrosc Res. 23(11):863-869.

44. Ajun W, Yan S, Li G, Huili L. Preparation of aspirin and probucol in combination loaded chitosan nanoparticles and in vitro release study. Carbohydr Polym. 2009;75(4):566-574.

45. Thybo P, Pedersen BL, Hovgaard L, Holm R, Mullertz A. Characterization and physical stability of spray dried solid dispersions of probucol and PVP-K30. Pharm Dev Technol. 2008;13(5): 375-386.

46. Takka S, Cali AG. Bile salt-reinforced alginate-chitosan beads. Pharm Dev Technol. 2012;17(1):23-29.

47. Awasthi R, Kulkarni GT. Development of novel gastroretentive drug delivery system of gliclazide: hollow beads. Drug Dev Ind Pharm. 2014;40(3):398-408.
Drug Design, Development and Therapy

\section{Publish your work in this journal}

Drug Design, Development and Therapy is an international, peerreviewed open-access journal that spans the spectrum of drug design and development through to clinical applications. Clinical outcomes, patient safety, and programs for the development and effective, safe, and sustained use of medicines are a feature of the journal, which
Dovepress

has also been accepted for indexing on PubMed Central. The manuscript management system is completely online and includes a very quick and fair peer-review system, which is all easy to use. Visit http://www.dovepress.com/testimonials.php to read real quotes from published authors. 